Barbara Pausch

Translation of German Dialects and Colloquial Speech into English: Language, Backgrounds, and Attitudes

\begin{abstract}
nalyzing dialects and colloquial speech, this study focuses on 1 four research questions: What are the participants' attitudes towards dialect and colloquial speech and their usages? Are their language backgrounds reflected in the language attitudes? How are the German sub-standards translated into English? How are the language attitudes reflected (or not) in the translations?
\end{abstract}

\title{
Introduction
}

So-called sub-standards, dialects and colloquial speech have always been considered difficult to translate, mainly due to their socio-cultural embedding. Antoine Berman, a translation theorist who worked mainly with literary translation, states the following: "Unfortunately, a vernacular clings tightly to its soil and completely resists any direct translating. [It] is by its very nature more physical, more iconic" than standard languages (Berman 286). While vernaculars might not be an issue for translators of academic texts, these sub-standards are used widely in literature, which tends to create problematic situations for literary translators. In addition to having to find a way to transfer the dialect into the target language, which is often claimed to be impossible (Brembs 2004), the translator also indirectly has to make a statement about the status of these sub-standards. What target register, dialect, or colloquial coloring does the translator judge to be equivalent with the source dialect or colloquialism? What is the status of this register, dialect, or colloquial coloring in the target culture? What is the status of the 
dialect or colloquial coloring in the source culture? Translations compel the translators to consider their language attitudes towards dialects and colloquial speech, both in their own culture but also in the culture that the source text was written in and is embedded in. They need to consider, judge, and transfer several levels of embedding and linguistic information, namely the diatopic (regional, local), diastratic (social), and diaphasic (stylistic) characteristics of the dialect or colloquialism (Albrecht 2005).

Bernstein's deficit hypothesis illustrates their perceived inferiority compared to standard languages (Barbour 1987, Bernstein 1971). Labov's difference theory (1969) challenges Bernstein's view by claiming that both standard and non-standard varieties are necessary and natural. Ferguson's concept of diglossia was among the first to address these language attitudes: due to prestige differences, speakers of the prestigious standard usually avoid the sub-standard (1959). In this study, however I use dialect and colloquial speech translations as a basis for analyzing language attitudes towards German and English sub-standards.

In this study, I use the challenging dialect and colloquial speech translations as a basis for analyzing language attitudes towards German and English sub-standards. The study focuses on four research questions: What are the participants' attitudes towards dialect and colloquial speech and their usages? Are their language backgrounds reflected in the language attitudes? How are the German sub-standards translated into English? Are they translated at all, and if so, on what level? Are the language attitudes reflected in the translations, and if so, how? The data for this study is drawn from twenty written surveys that were distributed among graduate and undergraduate students in a modern languages department of a large western Canadian university. The participants were asked to translate short excerpts of three German texts (characterized by 
strong influence of Silesian/ Bavarian dialect and colloquial speech) into English. Furthermore, the participants were asked to share their language and translation background and their views on the use of dialect and colloquial speech.

The language attitudes are analyzed qualitatively with a combination of direct and indirect approaches following Garrett et al. (2003). Translation issues (e.g. gain and loss, levels/ types of translations) are addressed following Bassnett (2002). The language and translation backgrounds of the participants are revealed mainly through quantitative analysis of the surveys (Milroy and Gordon 2003).

\section{Dialect and Diglossia}

There are numerous definitions for the term 'dialect', among them the following: "the usage or vocabulary that is characteristic of a specific group of people" (Princeton University 2010), "a particular from of a language that is peculiar to a specific region or social group" ("dialect" 2009), "a variety of language which differs from other varieties in terms of vocabulary, grammar and pronunciation (accent)" (Edwards 1985: 19). In addition to the regional or social coloring of dialects that is addresed in many definitions, these substandards are also associated with a certain status. "We should also note that there exists more than a simple dichotomy between standard and non-standard dialect; there are often status hierarchies" (Edwards 1985: 21). A language environment with more than one language standard, one of them the 'lower' and the other one the 'higher' standard, is called a diglossic environment.

Diglossia is a "language situation characterized by a conspicuous divergence between a literary or 'high' variety $(\mathrm{H})$ and the colloquial or 'low' variety (L)" ("Diglossia" 1999). Ferguson, the initiator of the concept of diglossia, originally summarized it as follows: 
DIGLOSSIA is a relatively stable language situation in which, in addition to the primary dialects of the language (which may include a standard or regional standards), there is a very divergent, highly codified (often grammatically more complex) superposed variety, the vehicle of a large and respected body of written literature, either of an earlier period or in another speech community, which is learned largely by formal education and is used for most written and formal spoken purposes but is not used by any section of the community for ordinary conversation. (Schiffman 1998)

In his definition, Ferguson addresses the prestige differences that exist between the primary dialects and the superposed variety of the language. The superposed variety is respected, formal, written, and complex, whereas the primary dialects are regionalized and colloquial. The prestigious standard appears to be reserved for certain situations and (educated) speakers. According to Schiffman, this is the habitual case in diglossic situations: "In most diglossias examined, $\mathrm{H}$ [the higher variety] was more highly valued (had greater prestige) than was L [the lower or sub-standard variety]. The $\mathrm{H}$ variety is that of 'great' literature, canonical religious texts, ancient poetry, of public speaking, pomp and circumstance. The $\mathrm{L}$ variety is felt to be less worthy, corrupt, 'broken,' vulgar, undignified, etc." (Schiffman 1998). Edwards confirms these findings, stating that since "there is no linguistic or aesthetic basis for the superiority or inferiority of dialects" (Edwards 1985: 22) these judgments are based on the social prestige of the sub-standards (or the lack thereof) and the power of the speakers.

The problematic status of sub-standards has also been considered and analyzed by other theorists, among them Bernstein, Labov, Hallyday, and Bourdieu. Bernstein's deficit hypothesis illustrates their perceived inferiority compared to standard languages. According to Bernstein, there are 'restricted codes' and 'elaborated codes', with the elaborated code being the high-standard variety and 
the restricted code being the sub-standard variety. The restricted codes are considered inferior, at least on a grammatical level, and they are connected to the working and lower classes, hence they are perceived to be less prestigious. Furthermore, Bernstein claims that working-class children, since they are only able to speak a restricted code, are less effective and successful in communication (Barbour 1987, Bernstein 1971). This bold statement caused much disagreement and discussion. Among others, Labov's difference theory (1969) challenges Bernstein's view by claiming that both standard and non-standard varieties are necessary and natural and despite their difference none of them is inferior. Furthermore, theorists asserted that the working-class children's communication problems are due to their restricted education and speaking opportunities as well as their lack in communicative confidence, however, not to their inferior dialect (Hallyday 1973).

Bourdieu's sociological studies of the 1960s and 1970s also dealt with language standards and sub-standards. According to Bourdieu, language is part of every person's symbolic capital that can be mobilized and interchanged with other forms of material capital. Thus, speaking a sub-standard, which is considered less prestigious than the standard, could indeed have negative consequences for the speaker (Bourdieu 1977).

\section{Language Attitudes}

Despite discussions surrounding the status of sub-standards, stereotypes and judgments about languages, i.e. language attitudes, exist. Speakers do indeed perceive some language varieties to be more or less prestigious than others. Language attitudes, expressed through perceived prestige differences, were already addressed in 1959 in Ferguson's concept of diglossia. However, while the concept of attitudes is accepted and widespread in social psychology, the 
definition of the concept of language attitudes has been debated a lot in the linguistic context. Sarnoff's definition of attitudes is a valuable starting point: "a disposition to react favourably or unfavourably to a class of objects" (Sarnoff 1970: 279). Thus, attitudes are evaluative orientations towards social constructs. Since they are dispositions, i.e. habitual inclinations or habitual tendencies, they are at least somewhat stable and measurable (Garrett et al. 2003). Oppenheim gives a more detailed definition of the concept of attitude:

A construct, an abstraction which cannot be directly apprehended. It is an inner component of mental life which expresses itself, directly or indirectly, through such more obvious processes as stereotypes, beliefs, verbal statements or reactions, ideas and opinions, selective recall, anger or satisfaction or some other emotion and in various other aspects of behavior. (Oppenheim 1982: 39)

Attitudes have a threefold structure, which includes cognitive, affective, and behavioral components. They are cognitive since they are based on and contain beliefs about the world around us, they are affective since they involve feelings, and they are behavioral since they can influence our behavior (Garrett et al. 2003). Furthermore, attitudes are learned through human socialization, i.e. they are quite persistent, and they are "socially-structured and socially-structuring phenomena" (Garrett et al. 2003: 5). Language attitude research aims at assembling a "record of overt [and covert] attitudes towards language, linguistic features and linguistic stereotypes" (Labov 1984: 33). Language attitude research has been focusing on several different topics; according to Baker (1992), at least eight different categories can be listed: attitudes to language variation, dialect, and speech style; to learning a new language; to a specific minority language; to language groups, communities, and minorities; to language lessons; to uses of a specific language; to language preference; and finally attitudes of parents to language learning 
(Baker 1992). For my project, attitudes to language variation, dialect, and speech style and attitudes to uses of a specific language are most important.

\section{Language Attitude Research}

Language attitudes can be studied with three different approaches: the societal treatment approach, the direct approach, and the indirect approach (Garrett et al. 2003: 14f). The societal treatment approach analyzes the treatment of certain languages, language varieties, and speakers. Studies using this approach are, for example, ethnographic studies, participant observations, or the analysis of sources in the public domain (e.g. governmental or educational documents, advertisements, novels). This approach has, in part, been criticized for lacking precision. Thus, it is more appropriate for initial analyses (Garrett et al. 2003: 15f).

The direct approach is more obtrusive but therefore also more specific than the societal treatment approach. It works with elicitation, i.e. asking questions about language use, evaluation, preferences, etc. (Garrett et al. 2003: 16). The main issue in this approach is that it is debatable whether the participant's answers can be interpreted as being truly representative of their actual dispositions, preferences, likings etc. Many studies, however, have proven that the direct approach is a very useful tool to gather data about people's language attitudes, especially if the approach is then combined with others, e.g. indirect approaches (Garrett et a. 2003: 24ff).

The indirect approach uses more subtle techniques than the direct approach; among others, it observes people's subconscious behavior and it observes participants, without them being aware of the actual goal of the study. Research ethics are usually the main concern in studies with indirect and 'deceiving' techniques (Garrett et al. 2003: 
51ff). In language attitude research, the matched-guise technique (MGT) has generally been perceived as the most valuable technique. In studies using the MGT, participants hear audio-recordings of one speaker reading a text several times, pretending to be a different person each time. After each instance of hearing the text, the listeners have to rate the speaker. Since the speaker is always the same one, the answers then reveal the participants' attitudes to the different dialects that the speaker is asked to produce (Garrett et al. 2003: 17).

\section{Data and Participants}

The data for my study is drawn from written surveys that were distributed among graduate and undergraduate students in a modern languages department of a large western Canadian university. A total of twenty-five surveys were distributed electronically via email or in person via paper copy. Out of the twenty-five distributed surveys, twelve were filled out and returned. The participants were chosen based on a pre-screening of their language background, since they had to be fluent in both German and English, should have lived both in an English-speaking and a German-speaking environment, and have some background in translation. The pre-screenings were done orally or via email. During these pre-screenings, the potential participants were also informed about the setup of the survey and the consent form. Furthermore, they were informed about the order in which they should fill out the survey since changing the order could potentially have influenced the results. The following is an initial overview of the participants: 


\begin{tabular}{|l|c|}
\hline $\begin{array}{l}\text { Total Number of } \\
\text { Participants }\end{array}$ & 12 \\
\hline \multicolumn{2}{|l|}{} \\
\hline Female & 10 \\
\hline Male & 2 \\
\hline \multicolumn{2}{|c|}{} \\
\hline Undergraduate Student & 8 \\
\hline Graduate Student & 4 \\
\hline \multicolumn{2}{|c|}{} \\
\hline Native speaker of German & 5 \\
\hline Native speaker of English & 4 \\
\hline Other & 3 \\
\hline
\end{tabular}

Table 1: Initial Overview

All in all, the participants' age range was 21 to 41 . Unfortunately, the native language of the participants could not be determined in all cases. The total of German and English native speakers is nine. The group of remaining participants comprises one French native speaker and two participants, who did not indicate their native language.

\section{Setup of the Survey}

The survey (see Appendix) contained three parts: a first part, where the participants were asked to translate short excerpts of three German texts into English, a second part, where they were asked questions about the translations, and a third part, which focused on the personal information of the participants. Several of the drawbacks of written surveys (Garrett et al. 2003: 27ff; Garrett 2010: 43-46) were considered and if possible avoided. First, there were no hypothetical questions such as "what would you say if...." Second, strongly slanted or "'loaded' words that tend to push people 
into answering one way" were avoided and the sensitive nature of the topic of colloquialisms and dialects was approached as unbiased as possible (Garrett 2010: 43). Third, in order to lessen the social desirability bias, "the tendency for people to give answers to questions in ways they believe to be "socially appropriate" (Garrett 2010: 44), the participants were informed that the survey results would be interpreted anonymously. Fourth, since the researcher was not present when the surveys were filled out, the interviewer's paradox, i.e. the tendency to be affected by the characteristics of the researcher (Garrett et al. 2003: 29), and the acquiescence bias, i.e. the tendency "to agree with an item, regardless of its content" (Garrett 2010: 45), could be lessened.

The short excerpts that had to be translated in the first part of the survey were adaptations of three different texts, namely Gerhart Hauptmann's Die Weber, Alexa Hennig von Lange's Relax, and a set of Bavarian sayings. Die Weber is a late-nineteenth century German drama that is characterized by a strong influence of the Silesian dialect. Silesian is a German dialect of the East Middle German dialect group, spoken, to some extent still today, in Silesia (today part of Poland, the Czech Republic, and Germany), in the Sudetenland (today part of the Czech Republic), and in the diasporas (Ullmann 1982, Schildberg-Schroth 1983). Relax is a 1997 coming-ofage novel that is characterized by a very strong influence of colloquial speech and youth language (Hennig von Lange 1997). The Bavarian sayings were collected through an internet search (Schmidtmann 2010). The dialect used in the sayings is an example of the Upper Bavarian dialect, which belongs to the Upper German dialect group and is spoken in Southern Bavaria (Zehetner 1985).

The second part of the survey asked the participants about their translations and their translation choices. Furthermore, the participants were asked to share their views on the use and 
appropriateness of dialect and colloquial speech. The goal of these open-ended questions was to guide the participants towards considering the kind and nature of difficulties that they had during the translation process. Furthermore, since it could be expected that the colloquial and dialectal elements would cause the main problems, the second part of the survey wanted to elicit the subjects' attitudes towards the use and the appropriateness of these non-standard forms of speech.

The third part of the survey asked for the participants' language and translation backgrounds which were expected to have an influence both on the translation results but also on the language attitudes. The questions were mainly closed-ended (at least in parts) in order to receive comparable results.

\section{Methodology}

In my study, I want to combine direct and indirect approaches; however, instead of using the matched-guise technique as my indirect component, I want to analyze translations that were produced by the participants. Furthermore, I want to examine whether the translations indirectly reflect the participants' attitudes as stated on the questionnaires, as well as their language and translation background. The analysis will be mainly qualitative. First, the open- and closed-ended written response questions about the attitudes and language backgrounds will be collected from the questionnaires and interpreted. Second, the language and translation backgrounds of the participants will be collected and interpreted in relation to the participants' stated attitudes. Some of the information on language and translation backgrounds will be illustrated quantitatively (Milroy and Gordon 2003). In a third step, the attitudes expressed indirectly in the translations will be collected and, if possible, related to the attitudes that were expressed directly. 
Any translation issues, for example, an analysis of the levels and types of translations will be addressed following Bassnett (2002).

Results

\begin{tabular}{|c|c|c|c|c|}
\hline & $\begin{array}{l}\text { Time } \\
\text { spent in } \\
\text { English- } \\
\text { speaking } \\
\text { country }\end{array}$ & \begin{tabular}{l}
\multicolumn{1}{c}{ Time } \\
learning \\
English
\end{tabular} & $\begin{array}{l}\text { Time } \\
\text { spent in } \\
\text { German- } \\
\text { speaking } \\
\text { country }\end{array}$ & $\begin{array}{r}\text { Time } \\
\text { learned } \\
\text { German }\end{array}$ \\
\hline \multirow{4}{*}{$\begin{array}{l}\text { Individual } \\
\text { Responses } \\
\text { (in order } \\
\text { of } \\
\text { duration) }\end{array}$} & $\begin{array}{l}\text { Up to } 1 \\
\text { year ( } 2 \\
\text { participants) }\end{array}$ & & $\begin{array}{c}\text { 1-2 years } \\
(3 \\
\text { participants })\end{array}$ & $\begin{array}{c}\text { 4 years } \\
(1 \\
\text { participant) }\end{array}$ \\
\hline & $\begin{array}{c}\text { 4-5 years } \\
(2 \\
\text { participants })\end{array}$ & $\begin{array}{c}\text { 5-10 years } \\
(2 \\
\text { participants })\end{array}$ & $\begin{array}{c}\text { 5-10 years } \\
(2 \\
\text { participants })\end{array}$ & $\begin{array}{c}\text { 5-10 years } \\
(2 \\
\text { participants })\end{array}$ \\
\hline & & $\begin{array}{l}\text { More than } \\
10 \text { years } \\
(6 \\
\text { participants) }\end{array}$ & $\begin{array}{l}\text { More than } \\
10 \text { years } \\
(5 \\
\text { participants) }\end{array}$ & $\begin{array}{l}\text { More than } \\
10 \text { years } \\
(4 \\
\text { participants) }\end{array}$ \\
\hline & $\begin{array}{l}\text { No } \\
\text { response } \\
\quad(8 \\
\text { participants) }\end{array}$ & $\begin{array}{l}\text { No } \\
\text { response } \\
\quad(4 \\
\text { participants) }\end{array}$ & $\begin{array}{l}\text { No } \\
\text { response } \\
\quad(2 \\
\text { participants) }\end{array}$ & $\begin{array}{l}\text { No } \\
\text { response } \\
\quad(5 \\
\text { participants) }\end{array}$ \\
\hline
\end{tabular}

Table 2: English and German Proficiency

These findings indicate that the participants have a high proficiency in both English and German, despite not all of them being native speakers of these two languages. All of them have had some kind of formal education (elementary school, high school, or university) in German and English. Many participants did not 
indicate for how long they had been speaking their native language. Thus, the columns 'Time learned English/ German' lack some information. The four people who did not indicate 'Time learned English' are native speakers of English. The five people who did not indicate 'Time learned German' are part of the group of German native speakers.

All of the participants have spent time in English-speaking and German-speaking countries. The majority of participants did not mention that they currently live in Canada and that they have been living there for years. Thus, the column 'Time spent in Englishspeaking country' lacks many responses. The two participants, who did not indicate their 'Time spent in German-speaking country' are German native speakers. Therefore, it can be assumed that they spent considerable time in a German-language environment. All in all, the considerable amount of time that all participants spent in German-speaking and English-speaking countries implies that they have been exposed to a variety of dialects, regional colorings, and colloquialisms in both languages.

\begin{tabular}{|c|c|}
\hline $\begin{array}{c}\text { Country } \\
\text { (multiple } \\
\text { answers possible) }\end{array}$ & $\begin{array}{c}\text { Number of } \\
\text { Participants }\end{array}$ \\
\hline Germany & 11 \\
\hline Austria & 4 \\
\hline Switzerland & 2 \\
\hline
\end{tabular}

Table 3: Residence in German-speaking Countries 


\begin{tabular}{|ll|}
\hline \multicolumn{2}{|l|}{ German Dialects/ Regional Colorings } \\
\hline$\bullet \quad$ Saarland dialect (Saarländisch) / Swabian \\
(Schwäbisch) \\
\hline$\bullet \quad$ East-Westphalian (Ostwestfälisch) \\
\hline$\bullet$ & Bavarian \\
\hline$\bullet$ & Swiss dialect \\
\hline$\bullet$ & Southern German coloring \\
\hline$\bullet$ & Mix of German dialects \\
\hline
\end{tabular}

Table 4: Knowledge of German Dialects

The majority of participants reported that they speak no English dialect and have no English regional coloring either. Only one participant mentioned that she speaks Trini English (English of Trinidad and Tobago). However, since English dialects and regionalisms are not discussed as often as German dialects, the participants might simply not be aware of them as much as they are aware of their German dialects. Six participants indicated that they speak a German dialect (with a variety of dialects from southern, middle, and northern Germany; see table 4). The remaining participants indicated that they speak Standard German. Nevertheless, the variety of dialects that was mentioned and the participants' long stays in German-speaking environments confirms that they either speak or at least are familiar with German dialects and regional colorings.

\section{Translation Backgrounds}

Only one of the participants has never taken a translation class, five participants have taken a theory of translation class, and eleven participants have taken or are currently taking a practical 
translation class (multiple answers were possible). The participants have translated a variety of languages, namely German-English (6 participants), English-German (2 participants), English-French, French-English, German-Spanish, Spanish-German, GermanItalian, English (2 participants), German (2 participants), Italian, and Swahili (some participants did not indicate the translation direction). Five participants do not translate on a regular basis, six participants translate for classes, one participant translates for fun, and one translates for work (again, multiple answers were possible). Despite the variety of translation backgrounds, the participants are rather skilled and experienced translators. The high number of participants that have translated from German to English particularly indicates that they have dealt with translation problems, similar to the ones posed in the survey, before.

\section{Reported Difficulties with Original Texts and Translations}

Two participants, who are German native speakers, thought that "nothing" was hard about the original texts. The ten remaining participants suggest that the dialect was the main source of confusion when trying to comprehend the original texts: the "unfamiliar words", the mix of "dialect and standard variety", trying to understand what the words meant, trouble understanding and finding dialect sayings, and the mix of dialect and colloquial register. All participants (independently of their native language) reported difficulties with the translations. Some mentioned that it was hard for the translations to make sense in English (mainly German native speakers who are less familiar with English). Some named the lack of direct translations as a cause for translation difficulties. Furthermore, conveying the structure and transferring the connotations to English was found difficult: "finding an appropriate translation of the meaning and cultural background" and "finding 
sentences or expressions that correspond to the German meaning, but sound English."

The reasons for the translation difficulties were on the one hand rather clear and unambiguous: the missing context and the missing familiarity with English dialects, proverbs, and slang vocabulary. On the other hand, there were also rather complex reasons for the translation difficulties. The most proficient translator of the participants, namely the professional translator, mentioned that "meaning gets lost in translation". One of the non-native speakers of German stated that "understanding the words [in the German texts] doesn't mean understanding their meaning, especially in dialects". A German native speaker, who had difficulties transferring the meaning to English, stated that "some idioms are culture-specific, so you also have to translate the culture". Here, the participants are alluding to the diatopic, diastratic, and diaphasic embedding of the dialects or colloquialisms (Albrecht 2005) that was discussed earlier. In everyday uses of the dialect, these embeddings do usually not become obvious, they are unconscious, but the translation task forces the participants to consider these aspects of dialects.

\section{Reasons for the Translation Choices}

The majority of the participants (with varying language backgrounds) indicated that they made an effort to transfer the dialects and colloquialism. Three participants, however, indicated very clearly that they thought it was impossible to translate the dialects and, thus, they ignored them. "[I] ignored the fact that it was dialect, did however try and indicate the colloquial register". Interestingly, the three participants have varying language backgrounds: one English native speaker, one German native speaker, and one participant with undisclosed native language. Furthermore, all of them are rather experienced translators who 
have taken practical and theoretical translation classes in varying languages. They are, however, connected by not being able to speak a German dialect.

Translation of the Dialect Passages - Relation to the Participants' Attitudes to Dialects and Dialect Uses

Many participants expressed their fondness of dialects: "[Dialekte sind] der Hammer!" (Dialects are awesome!), "I think they are very interesting, and I'm interested in learning more about German dialects". However, the dialects used in the first and third German excerpts were not translated by any participant. Nevertheless, most of them claimed that they had at least attempted a translation. Only one participant, who is a German native speaker, tried to indirectly translate the dialect colorings by adding "that they [the texts] are originally Bavarian or that the spoken parts in Hauptmann are dialectal." This is, however, more of an intralingual rewording or rephrasing than an actual interlingual translation, or translation proper (Bassnett 2002: 22). Since the participants' English translations show no dialectal colorings it is hard to address the third research question, i.e. it is hard to assess how the language attitudes would have been reflected in the translations. Nevertheless, the participants' attitudes to the status and use of dialect can be analyzed independently of the translations.

\section{Pro-dialect Group}

There was a clearly determinable pro-dialect group, who expressed very positive attitudes to the status and use of dialects. Interestingly, the five pro-dialect participants in this group were also part of the group who stated that they speak a German dialect. The pro-dialect group feels that dialects make languages unique. Furthermore, they think that dialects reflect and express more of the 
culture than the standard varieties. One participant thinks that dialect use is always appropriate, even in "primary and secondary schools". Another participant states that it is the dialogue partners who should be able to decide on the language use: "I think it is always appropriate when the dialogue partners deem it to be". It seems like being able to speak a dialect makes these sub-standards less intimidating. Also, it makes the dialects more personal and culturally meaningful. Although the pro-dialect group did not manage to translate the German dialects into English, they assigned a far wider range of domains of use (home, friends, work, school, etc.) to them than the other participants.

\section{Contra-dialect Group}

The contra-dialect group, consisting of seven participants, assigned a very narrow range of domains of use to the dialects. The contra-dialect group comprises mainly non-dialect speakers. It seems like the lack of close familiarity with a dialect triggers more negative attitudes to its use and status. The second group claims that dialects should be "kept or spoken at home" in non-formal and nonprofessional situations. While the in-group attribute of dialect speakers is sometimes admired, the in-group characteristic means that speaking a dialect can also be used to exclude other people who are not familiar with it: "hard to understand if you're not a native speaker". This in-group/ out-group mentality seems to differentiate the pro-dialect group from the contra-dialect group.

The statements of the contra-dialect group remind of some of the findings discussed in the literature review of Schiffman's (1998) findings about the lack of prestige of sub-standards were reflected by the statement that "having a dialect given in a text usually gives you an idea or a prejudice about the people [speaking the dialect]." Furthermore, this alludes to Edwards's (1985) statement about the 
correlation between the prestige or rather the lack of prestige of the dialect and the speakers of the dialect. The statement that dialect "usually gives an impression of more spoken than written (and thus less formal) language" reminds of Labov's difference theory (1969), both varieties are necessary and natural but they are used in different domains. This restriction to certain domains is exactly what the contra-dialect group postulates.

Translation of the Colloquial Passages - Relation to the Participants' Attitudes to Colloquial Speech and Its Uses

The participants' attitudes to the status and use of colloquial speech were rather homogenous. All subjects think that colloquialisms are acceptable and appropriate in informal situations, when talking to family and friends. Thus, all participants have a positive attitude to colloquial speech when used within its informal domain. However, most participants are aware of the negative status of colloquial language. Nevertheless, they find it necessary "to certain relationships in any language, it defines the relationship to the person you talk to and to the topic". Again, this alludes to Labov's difference theory. The statement that colloquial language "is sometimes looked down upon although it is more personal" also points to the negative language attitudes that were addressed in the introductory sections. The analysis of the attitudes showed no relation to language or translation backgrounds. However, an analysis of the translations and the degree to which the German colloquial register was transferred to English indeed made it possible to classify two groups of participants, namely a younger procolloquial group and an older pro-colloquial group. Thus, there was a divide in the degree of colloquial translation according to age. 


\section{Younger Pro-colloquial Group}

The younger pro-colloquial group (seven participants) had an average age of 24 . In her comments, one of the younger participants alluded to the age divide by stating the following: "[colloquial speech is] mostly desired in youth, when you talk to people in the same age group". Another young participant addressed the hierarchical nature of conversations. According to this hierarchy, colloquialism should only be used if both people are "on the same level", for example "a student with another student". These comments give the impression that the colloquial varieties are mostly used by younger speakers. A person from the older pro-colloquial group underlines this by stating that "I don't have this slang vocabulary".

The younger group used a variety of tools to transfer the German colloquial register to their English translations. They addressed both the structural/ paradigmatic as well as the lexical/ linguistic level (Bassnett 2002). Structural choices that transferred the colloquial nature of the original text were, for example, the use of contractions such as "gonna" or the dropping of word-final 'g' in "freakin". Lexical colloquialisms were used most commonly, for example, "dude", "buddy", "freezing my ass off", "sweating like a pig". This indicates that the younger group is very comfortable with the colloquial speech, whereas the older group feels more hesitant to use it.

\section{Older Pro-colloquial Group}

The older pro-colloquial group (five participants) had an average age of 30 , so there was a considerable age difference of six years to the younger group. While the older group's attitudes to the use of colloquial language are just as positive as the younger group's attitudes: "I feel it is something important because it makes culture so much more interesting", "[it can] make people feel more comfortable", they transferred fewer of the colloquialisms. An 
analysis of the translations showed that while the lexical level was also addressed, the structural level was not. Furthermore, there were fewer instances of lexical colloquialisms than in the younger group. While the younger group transferred an average of six colloquialisms per translator, the older group transferred an average of only three colloquialisms per translator.

\section{Conclusion}

My findings suggest several responses to the research questions posed in the beginning. Regarding the participants' attitudes to dialect and dialect use, a pro-dialect group and a contra-dialect group could be found. Furthermore, a relation between the affiliation with either the pro-dialect or the contra-dialect group and the participants' own language backgrounds could be detected. Generally, the pro-dialect attitude depended on the speaker's own dialect proficiency. The participants' attitudes to colloquial speech and its use were generally positive. However, the participants assigned a very narrow range of domains of use to colloquial speech, namely informal settings such as family of friends. Regarding the translation of German sub-standards, there was a significant difference between dialects and colloquial speech. While dialect was not translated at all, colloquial speech was translated on both the structural and the lexical level (dependent on age of participants). Regarding the reflection of the language attitudes in the translations, the divide between dialect and colloquial speech was noticeable again. Since the dialects were not translated it is difficult to decide whether and on what level the attitudes would have been reflected. The colloquialisms, however, were translated and the translations differed depending on the participants' age. Thus, the attitude that colloquial speech is reserved for younger people is also reflected in the translations. 
For future research, this study could be improved and expanded in several ways. First, the translation of the dialect excerpts could be left out, contextualized further, or revised to be used with the matched-guise technique. In order to use this technique, the dialect parts would be spoken and recorded and then replayed to collect the participants' language attitudes in that way. Second, the written surveys could be followed with personal interviews in order to find out more about the language and translation backgrounds. Third, the personal interviews could also be used to address the somewhat vague attitudes to dialects further.

Finally, the implications of the missing dialect translations must not be left unaddressed. Although almost all participants stated positive attitudes to dialects and dialect uses none of them managed to translate them. Several causes could have triggered this partly contradictory situation. First, dialect translations are indeed considered very complicated and complex, so the participants could have felt overwhelmed by the task. Second, the survey topic and questions could have had an impact on the survey responses. The participants were probably aware of the researcher's goals and 'preferred answers'. However, they were also aware of the negative status of dialects. Thus, in order to 'give the desired answers', their responses could have been influenced towards making them more pro-dialectal, without being able to apply these positive answers in the practical translations. Third, the dilemma also has pedagogical implications. In most language classes, dialects are not addressed (enough). Thus, learners feel intimidated by them or they are simply not even aware of them. Furthermore, many translation classes do not address dialect either. Consequently, students are not given the necessary tools and experience to work with these types of translation tasks. Therefore, it is very important, both for language and translation classes to address dialects as early as possible, 
especially in a language such as German, which has a multitude of dialect varieties.

\section{Works Cited}

Albrecht, Jörn. Übersetzung und Linguistik. Tübingen: Narr, 2005. Print.

Baker, C. Attitudes and Language. Clevedon: Multilingual Matters, 1992. Print.

Barbour, Stephen. "Dialects and the Teaching of a Standard Language: Some West German Work." Language in Society 16.2 (1987): 227-43. Print.

Bassnett, Susan. Translation Studies. $3^{\text {rd }}$ ed. London, New York: Routledge, 2002. Print.

Berman, Antoine. "Translation and the Trials of the Foreign." The Translation Studies Reader. Ed. Lawrence Venuti. $2^{\text {nd }}$ ed. New York, London: Routledge, 2004. 276-89. Print.

Bernstein, Basil. "A Socio-Linguistic Approach to Social Learning." Class, Codes and Control, Volume I. Ed. Basil Bernstein. London: Routledge \& Kegan Paul, 1971. 118-43. Print.

Bourdieu, Pierre. "The Economics of Linguistic Exchanges." Social

Sciences Information 16.6 (1977): 645-68. Print.

"Dialect." The Oxford Pocket Dictionary of Current English. Oxford UP, 2009. Web. 07 August 2012. Web.

"Diglossia." The Blackwell Encyclopedia of Writing Systems. Ed.

Florian Coulmas. Blackwell Publishing, 1999. Web. 07 August 2012. Web.

Edwards, John. Language, Society, and Identity. Oxford: Basil Blackwell, 1985. Print.

Ferguson, Charles. "Diglossia." Word 15 (1959): 325-40. Print.

Garrett, Peter et al. Investigating Language Attitudes. Social Meanings of Dialect, Ethnicity and Performance. Cardiff: University of Wales Press, 2003. Print.

Garrett, Peter. Investigating Language Attitudes. Cambridge: Cambridge UP, 2010. Print. 
Halliday, M. A. K. "Foreword." Class, Codes and Control, Volume II. Ed. Basil Bernstein. London: Routledge \& Kegan Paul, 1973. ix-xvi. Print.

Hennig von Lange, Alexa. Relax. Hamburg: Rogner und Bernhard, 1997. Print.

Labov, William. The Study of Nonstandard English. Washington, DC: National Council of Teachers of English, 1969. Print.

. "Field Methods of the Project on Linguistic Change and

Variation." Language in Use. Eds. J. Baugh and J. Sherzer.

Englewood Cliffs: Prentice Hall, 1984. 28-53. Print.

Milroy, Lesley, and Matthew Gordon. Sociolinguistics. Method and Interpretation. Malden: Blackwell, 2003. Print.

Oppenheim, B. "An Exercise in Attitude Measurement." Social Psychology: A Practical Manual. Eds. G.M. Breakwell et al. London: Macmillan Press, 1982. 38-52. Print.

Princeton University. "About WordNet." WordNet. Princeton University, 2010. Web. 07 August 2012. Web.

Sarnoff, I. "Social Attitudes and the Resolution of Motivational Conflict." Attitudes. Eds. M. Jahoda and N. Warren. Harmondsworth: Penguin, 1970. 271-82. Print.

Schiffman, Harold. "Diglossia as a Sociolinguistic Situation." The Handbook of Sociolinguistics. Ed. Florian Coulmas. Blackwell Publishing, 1998. Web. 07 August 2012. Web.

Schildberg-Schroth, Gerhard. Gerhart Hauptmann - Die Weber. Grundladen und Gedanken zum Verständnis des Dramas. Frankfurt: Diesterweg, 1983. Print.

Schmidtmann, Achim. "Bayerische Sprüche." Sprücheportal. Achim Schmidtmann, 2010. Web. 07 August 2012. Web.

Ullmann, Klaus. Schlesien-Lexikon. $3^{\text {rd }}$ ed. Mannheim: Adam Kraft, 1982. Print.

Zehetner, Ludwig. Das bairische Dialektbuch. Munich: Beck, 1985.

Print. 


\section{Appendix: Survey}

\section{Translation - German to English}

Please translate the following short texts into English. Feel free to use a dictionary - or just go ahead and translate the texts in one go. Please follow the order of the survey, i.e. start with the translations (part I) and then do part II and III afterwards. If you have any questions feel free to email me!

\section{Part I: Translations}

Gerhart Hauptmann: Die Weber (adaptation)

„Des is a schee Lied, des!“ sagte er als die anderen zu singen anfingen.

„Und das muß anderscher wern, [...] jetzt uf der Stelle." beschwerte er sich.

„Ich will 'ne Mutter sein, daß d's weeßt!“" schrie sie.

Alexa Hennig von Lange: Relax (adaptation)

Alter, da frisst man 'n Stück Brot und is hinterher super-stoned. 
Nee ey, also entweder is mir schweinekalt oder ich fang' wie blöde an zu schwitzen.

„Hey Alte, kannste mich mal beraten?“ fragte sie die Verkäuferin.

Bavarian sayings (adaptation)

„Z dick bist net, aba für dei Gwicht z kloa." ist ein ironisches bayrisches Sprichwort.

„Liaba bsuffen und lusdig, als niachtern und bläd.“ sagen die Betrunkenen gern.

Wenn mal nichts klappt: „Und is da Weg a no so schteil, a bisserl wos geht allerweil.“ 


\section{Part II: Questions about the Translation}

1. What was hard or confusing about the original texts?

2. What was hard about the translations?

3. Why was it hard?

4. Why did you translate the texts like you did? Any reasons for the grammar and/ or word choices?

5. Generally, how do you feel about dialect (in German and English)?

6. Generally, how do you feel about colloquial speech (in German and English)? 
7. How do you feel about the use of dialect and colloquial speech (in any language)? In your opinion, when is it (in)appropriate? When is it desired? When or in which situations do you/ would you use it?

8. Please feel free to share any other comments! :-

\section{Part III: Personal Information}

1. For how long have you been speaking/learning English?

O native speaker $(\rightarrow$ skip question 2$) \quad$ O other: years

2. Where/how did you learn English?

O elementary school O high school

O university

O lived abroad $\rightarrow$ where? $\rightarrow$ for how long?

O other:

3. For how long have you been speaking/learning German?

O native speaker ( $\rightarrow$ skip question 4$) \quad$ O other: years 
4. Where/how did you learn German?

O elementary school O high school

O university

O other:

5. Have you ever lived in/traveled to Germany, Austria, or Switzerland?

O no O lived in for months/ years

O traveled to for weeks/ months

6. Do you speak a German or an English dialect or do you speak with a certain regional/dialectal coloring?

O no O yes:

7. Have you ever taken a translation class?

O no $\quad$ O yes $\rightarrow$ What kind? O theory $\quad \mathrm{O}$ practice

$\rightarrow$ Which language(s) did you translate?

8. Do you translate texts on a regular basis? 
O no O yes $\rightarrow$ why? O for class(es) O for fun O other:

9. Gender and Age

O female O male age:

Barbara Pausch is a freelance translator (German/English) and PhD candidate in Translation Studies at University of Alberta and Ludwig-Maximilians-University in Germany.

Contact: barbara.pausch@ualberta.ca; barbara.pausch@gmx.de 